University of Nebraska - Lincoln

DigitalCommons@University of Nebraska - Lincoln

Faculty Publications: Department of Teaching, Department of Teaching, Learning and Teacher Learning and Teacher Education

Education

2014

\title{
The Mathematical Nature of Reasoning-and-Proving Opportunities in Geometry Textbooks
}

\author{
Samuel Otten \\ University of Missouri, ottensa@missouri.edu \\ Nicholas J. Gilbertson \\ Michigan State University, gilbe197@msu.edu \\ Lorraine Males \\ University of Nebraska-Lincoln, Imales2@unl.edu \\ D. Lee Clark \\ Michigan State University
}

Follow this and additional works at: https://digitalcommons.unl.edu/teachlearnfacpub

Part of the Curriculum and Instruction Commons, and the Teacher Education and Professional

Development Commons

Otten, Samuel; Gilbertson, Nicholas J.; Males, Lorraine; and Clark, D. Lee, "The Mathematical Nature of Reasoning-and-Proving Opportunities in Geometry Textbooks" (2014). Faculty Publications: Department of Teaching, Learning and Teacher Education. 327.

https://digitalcommons.unl.edu/teachlearnfacpub/327

This Article is brought to you for free and open access by the Department of Teaching, Learning and Teacher Education at DigitalCommons@University of Nebraska - Lincoln. It has been accepted for inclusion in Faculty Publications: Department of Teaching, Learning and Teacher Education by an authorized administrator of DigitalCommons@University of Nebraska - Lincoln. 


\title{
The Mathematical Nature of Reasoning-and-Proving Opportunities in Geometry Textbooks
}

\author{
Samuel Otten, University of Missouri \\ Nicholas J. Gilbertson, Michigan State University \\ Lorraine M. Males, University of Nebraska - Lincoln \\ D. Lee Clark, Michigan State University \\ Corresponding author - Samuel Otten, 121B Townsend Hall, University of Missouri, \\ Columbia, MO 65211, USA; email ottensa@missouri.edu
}

\begin{abstract}
International calls have been made for reasoning-and-proving to permeate school mathematics. It is important that efforts to heed this call are grounded in an understanding of the opportunities to reason- and-prove that already exist, especially in secondary-level geometry where reasoningand-proving opportunities are prevalent but not thoroughly studied. This analysis of six secondary-level geometry textbooks, like studies of other textbooks, characterizes the justifications given in the exposition and the reasoning-and-proving activities expected of students in the exercises. Furthermore, this study considers whether the mathematical statements included in the reasoning-and-proving opportunities are general or particular in nature. Findings include the fact that the majority of expository mathematical statements were general, whereas reasoning-and-proving exercises tended to involve particular mathematical statements. Although reasoning-andproving opportunities were relatively numerous, it remained rare for the reasoning-and-proving process itself to be an explicit object of reflection. Relationships between these findings and the necessity principle of pedagogy are discussed.
\end{abstract}

Published in Mathematical Thinking and Learning, 16 (2014), pp 51-79.

doi 10.1080/10986065.2014.857802

Copyright (C Taylor \& Francis Group, LLC. Used by permission. 
Although the process of reasoning-and-proving is an integral component of mathematics (Hanna, 1995, 2000; Hersh, 2009), it has not been successfully integrated into students' school mathematics experiences (Stylianou, Blanton, \& Knuth, 2009). In the United States and Canada, for example, explicit attention to reasoning-and-proving is largely confined to a single geometry course at the secondary level (Hanna \& de Bruyn, 1999; Herbst, 2002). The situation is similar in countries such as Taiwan and Germany (Heinze et al., 2008), although the age at which students experience geometry may vary. When one construes reasoning-and-proving ${ }^{1}$ as a multifaceted process of making, refining, and justifying mathematical claims, the present isolation of reasoning-and-proving to geometry runs contrary to international recommendations for reasoning-and-proving to be present throughout the school mathematics curriculum (e.g., Ministry of Education, Science and Technology, 2011; National Council of Teachers of Mathematics [NCTM], 2000, 2009). Recently, in the United States, which is the context for the present study, the Common Core State Standards for Mathematics (National Governors Association \& Council of Chief State School Officers, 2010) identified the construction of viable arguments and the critiquing of others' reasoning as a key mathematical practice that should be developed with students at all levels. Underlying these recommendations are assumptions that link students' reasoning-and-proving experiences to their appreciation of its role in mathematics (Lampert, 1990; NCTM, 2000) as well as the development of deeper conceptual understanding of mathematical content (de Villiers, 1995; Dreyfus, 1999).

In conjunction with policy documents calling for an expanded role of reasoning-and-proving, the international research community has also identified reasoning-and-proving as an area of focus (Hanna \& de Villiers, 2008). In the United States, researchers have begun examining written curriculum materials to determine the extent and

1 We join Stylianides (2009) in using the term "reasoning-and-proving" to refer broadly to processes of conjecturing and justification that are meant to articulate a mathematical statement and convince oneself or others of its truth-value, wherein the justification or reasons given are acceptable to a particular classroom community if not the formal mathematical community. We use the term "mathematical proof" or "proof" to mean an explicit and deductive argument that would be accepted as valid by mathematicians knowledgeable in the particular content area. 
nature of reasoning-and-proving opportunities outside geometry. In particular, textbook studies have been conducted for the primary grades (Bieda, Drwencke, \& Picard, in press), for the middle grades (Stylianides, 2009), for secondary integrated textbooks (Davis, 2010), and for a variety of secondary algebra and pre-calculus textbooks (Thompson, Senk, \& Johnson, 2012). Taken together, these studies confirm that there is a scarcity of opportunities outside geometry for U.S. students to engage in or reflect on reasoning-and-proving. Similar results have been found with Canadian and Australian textbooks (Hanna \& de Bruyn, 1999; Vincent \& Stacey, 2008).

Although written curriculum materials are certainly not the sole influence on students' educational experiences in school mathematics, they are an important one (Cohen, Raudenbush, \& Ball, 2003; Grouws, Smith, \& Sztajn, 2004), which makes these textbook analyses a key step toward better understanding the current state of reasoning-and-proving opportunities and informing efforts to infuse reasoning-and-proving throughout the school curriculum. By omitting the secondary geometry course from analysis, however, these studies did not examine reasoning-and-proving where it is most prevalent. Moreover, textbook studies that have been situated in geometry (e.g., Öner, 2008, 2009) did not focus on reasoning-and-proving generally but, rather, focused on reasoning-and-proving as it specifically related to the use of dynamic geometry software. As the mathematics education community works to incorporate reasoning-and-proving throughout the school mathematics curriculum, it is important to not only look forward to the domains where reasoning-and-proving opportunities might be added but also to look back and reflect carefully on the nature of reasoning-and-proving opportunities that already exist. The present study promotes such reflection by characterizing the nature and extent of reasoning-and-proving opportunities in secondary geometry textbooks.

\section{Background}

Research on Students' Reasoning-and-Proving

For decades, students have had difficulty producing written proofs at both the secondary (Bell, 1976; Healy \& Hoyles, 2000; Martin \& Kelly, 
1998; Porteous, 1990; Senk, 1985; TIMSS, 1998) and university (Recio \& Godino, 2001; Weber, 2001) levels. One of the most commonly reported issues is students' misuse of empirical examples ${ }^{2}$ in the reasoning-and-proving process (Bieda, 2010; Bieda, Holden, \& Knuth, 2006; Chazan, 1993; Harel \& Sowder, 2007). In some studies, when students were asked to deduce a result, they instead provided an inductive argument using examples or diagrams that did not adequately address the generality of the mathematical claim (Healy \& Hoyles, 2000; Martin \& Harel, 1989; Williams, 1980). In other studies, students were found to be convinced by empirical evidence that mathematical results were true (Harel \& Sowder, 2007; Sowder \& Harel, 1998) and unconvinced by deductive forms of reasoning (Fischbein, 1982; Fujita, Jones, \& Kunimune, 2009; Healy \& Hoyles, 2000), in the latter case often failing to recognize that no further verifications were required once a correct deductive argument had been given. This constitutes a troubling reversal of logic as many students believe that a handful of confirming examples can establish the general truth of a mathematical result, whereas a deductive proof only establishes the truth of a single case, namely, "the case that is pictured in the associated diagram" (Chazan, 1993, p. 362).

Findings related to these two difficulties - struggling to produce proofs and misusing inductive arguments - are potentially linked in that, when asked to write a proof, students may be unable to do so at the moment and thus revert to an inductive argument rather than provide no response. Therefore, an inductive response does not necessarily imply that the student viewed it as a valid mathematical proof. Some studies, however, have taken up directly the question of students' conceptions of the nature of reasoning-and-proving. For example, Herbst and Brach (2006) interviewed geometry students (14-15 years old) who reported that the purpose of reasoning-and-proving was to allow them to demonstrate their reasoning and communication

2 We note that the empirical problem being described here has to do with the inappropriate use of inductive arguments to "prove" a general statement that requires a deductive justification. For example, it would be inappropriate to use 1 $+3=4$ and $3+5=8$ to "prove" that the sum of any two odd numbers is even. We do not mean to imply that there is no role for empirical reasoning in the reasoning-and-proving process. In fact, we agree with Polya $(1959,1981)$ that empirical reasoning is central to the formulation of conjectures and with Lakatos (1976) that empirical reasoning is central to the refinement of definitions and theorems. 
skills, rather than to verify claims or develop mathematical understanding. These results were confirmed by Soucy McCrone and Martin (2009) who also interviewed and observed geometry students, finding that they viewed the purpose of proof to be the application of recently learned theorems - not a mathematical process for establishing the truth of theorems. Elsewhere, geometry students were found to view deductive argumentation as an arbitrary exercise in logic that merely confirms what is already known to be true (Schoenfeld, 1988; Tinto, 1988).

These findings highlight the potential danger of students viewing reasoning-and-proving as an unnecessary or arbitrary exercise imposed on them by a teacher or textbook. Such conceptions of mathematical activities have been shown to be detrimental to students' subsequent learning of mathematics (Muis, 2004). Furthermore, it is noteworthy that much of this research was conducted with students in or beyond secondary geometry (e.g., Chazan, 1993; Herbst \& Brach, 2006; Selden \& Selden, 2003; Soucy McCrone \& Martin, 2009). In other words, the relatively extensive reasoning-and-proving experiences that students have in geometry do not seem to alleviate the known difficulties - in fact, it is possible that some problematic conceptions of reasoning-and-proving are specifically related to experiences in geometry.

\section{Theoretical Perspective}

The research described previously suggests that students' difficulties with reasoning-and-proving are not likely to be alleviated through mere exposure to deductive reasoning opportunities or various reasoning-and-proving activities (e.g., conjecturing, finding counterexamples). Instead, we must carefully consider the nature of the exposure and the mathematical context of the reasoning-and-proving activities. This study, therefore, focuses on students' "opportunities to learn" (Floden, 2002; Husen, 1967) to reason-and-prove that are embedded in the textbooks they use. We recognize that curriculum materials represent only one component of these opportunities to learn and that teachers have a more central role in shaping students' experiences through enactment (Tarr, Chavez, Reys, \& Reys, 2006). Nevertheless, curriculum materials have been studied in relation to student learning (Shield \& Dole, 2013), are a direct source of student tasks 
and homework assignments, and communicate to students in various ways (Herbel-Eisenman, 2007). Curriculum materials also shape what teachers do in the classroom (Grouws et al., 2004; McCrory, Francis, \& Young, 2008), thereby indirectly influencing student learning (Cohen et al., 2003; Ni \& Cai, 2011). Taken together, this suggests that it is reasonable to assume textbooks play an integral part in students' experiences with reasoning-and-proving.

Examinations of the reasoning-and-proving opportunities in textbooks can be aided and informed by the necessity principle. Harel and Tall (1991) identified the necessity principle as a standard for pedagogy that involves presenting subject matter in a way that encourages learners to see its intellectual necessity, "[f]or if students do not see the rationale for an idea, the idea would seem to them as being evoked arbitrarily; it does not become a concept of the students" ( $p$. 41 , emphasis in original). The necessity principle, then, is based on the notion that it is beneficial for students to engage with the intellectual underpinnings of a topic rather than as outsiders to the topic. In drawing on the necessity principle for a textbook analysis, we recognize not only the textbook's influence on classroom teaching, but also the direct pedagogical relationship between the text and the student. Furthermore, textbooks are often based on design principles (Hirsch, 2007) that are reflected in the embedded opportunities to learn, and the necessity principle can be used as a lens for interpreting those opportunities, even though teachers do not necessarily enact written materials as designed (Stein, Remillard, \& Smith, 2007).

There are several studies that suggest the necessity principle is often not being met with respect to reasoning-and-proving. First, Tinto's (1988) finding that geometry students viewed reasoning-and-proving as an arbitrary exercise imposed on them by an outside authority, such as a teacher or textbook, may be evidence that they did not see the intellectual need for deductive forms of reasoning. Second, many students do not recognize when deduction is required to establish a result with certainty (Harel \& Sowder, 2007; Porteous, 1990; Williams, 1980). Third, students who still entertain the possibility of finding a counterexample after seeing a correct deductive argument (Chazan, 1993; Fischbein, 1982; Healy \& Hoyles, 2000) may be failing to grasp the intellectual link between deduction and general claims. Furthermore, the finding that students view reasoning-and-proving as the application of theorems, rather than a means of establishing truth or 
generating knowledge (Herbst \& Brach, 2006; Soucy McCrone \& Martin, 2009), suggests these students may not yet perceive the intellectual role of reasoning-and-proving in mathematics.

In addition to providing an interpretive lens for these past findings, the necessity principle may guide the design of opportunities to learn that may move students beyond an empirical proof scheme (Harel \& Sowder, 2007) toward recognizing the need for deductive reasoning when establishing truth for an infinite number of cases. Indeed, instructional sequences and strategies have been developed (e.g., Buchbinder \& Zaslavsky, 2011; Stylianides \& Stylianides, 2009) to facilitate the intellectual transition from a sole reliance on empirical reasoning to the use and understanding of inductive and deductive reasoning together within the reasoning-and-proving process. Although it is an important first step to help students become aware of times when inductive reasoning is appropriate (e.g., developing conjectures) and when it is inappropriate (e.g., validating statements about infinitely many objects), the necessity principle pushes us further. We must also provide opportunities for students to see that deductive reasoning is necessitated by the situations in which inductive reasoning falters. Such understanding of deductive reasoning is especially crucial in mathematics because mathematics deals with general claims about entire, often infinite, classes of objects, and such claims can only be verified with certainty by deductive means.

In this study, we build on past research in two significant ways. First, we examine reasoning-and-proving in secondary-level geometry textbooks to complement the past work conducted in other areas and levels of mathematics. Second, we consider not only the frequency and type of reasoning-and-proving opportunities but also the nature of the mathematical statements around which reasoningand-proving takes place, thus refining existing analytic frameworks for textbook analysis. The research questions that guided the analyses were as follows:

$R Q 1$. What is the nature and extent of reasoning-and-proving opportunities contained in secondary-level geometry textbooks?

$R Q 2$. How do the reasoning-and-proving opportunities in geometry textbook exposition compare to the opportunities in student exercises? 
The context in which we address these questions is U.S. textbooks, but it is likely that other national contexts have similar kinds of reasoning-and-proving opportunities, even if they are not in the same proportions, and the broader issues related to our analytic framework and the ways in which these opportunities may necessitate deductive forms of reasoning are international in scope.

\section{Method}

Sample

This study involved six U.S. textbooks (see Table 1) designed for stand-alone geometry courses for students approximately 13-16 years old. The textbook series from which these geometry texts were drawn constitute the mathematics textbooks used by nearly $90 \%$ of the secondary population in the United States (Dossey, Halvorsen, \& Soucy McCrone, 2008). We have intentionally refrained from characterizing any of these textbooks at the onset of the study (e.g., as traditional or reform), although it may be appropriate to draw distinctions between textbooks based on the results of our analysis. It should be noted, however, that there is variation among the authors' and publishers'

Table 1. Geometry Textbooks Analyzed in This Study

\begin{tabular}{lllr} 
Title & Publisher & Authors & Year \\
\hline Geometry (CME) & Pearson & CME Project & 2009 \\
Geometry (Glencoe) & Glencoe McGraw Hill & Carter, Cuevas, Day, & 2010 \\
& & Malloy, \& Cummins & \\
Geometry (Holt) & Holt McDougal & Burger, Chard, Kennedy, & 2011 \\
& & Leinwand, Renfro, Roby, & \\
& & Seymour, \& Waits & 2008 \\
Discovering Geometry & Key Curriculum Press & Serra \\
(Key) & & & 2009 \\
Geometry (Prentice) & Pearson Prentice Hall & Bass, Charles, Hall, \\
& & Johnson, \& Kennedy & \\
Geometry (UCSMP) & Wright Group & Benson, Klein, Miller, \\
& McGraw Hill & Capuzzi-Feuerstein, & 2009 \\
& & Fletcher, Marino, Powell, & \\
& & Jakucyn, \& Usiskin
\end{tabular}

Note: For clarity, the term in parentheses next to the title is used to refer to each textbook. 
goals for the textbooks as stated in their prefaces and introductions.

Because we are examining the opportunities made available to students directly by the textbook, rather than opportunities in classroom enactment, we restricted our analysis to student editions of these textbook series. Although teacher's materials may provide important support for the way in which student materials are interpreted or enacted by teachers, and thus have been used informatively in some textbook analyses (e.g., Stylianides, 2009), we believe a teacher's enactment is not solely determined by the teacher's materials and so chose to code only the student edition.

Also excluded from analysis were supplementary activities such as "Activity Labs," "Explorations," "Projects," or additional materials available through the publisher's websites. Admittedly, some of these supplements did relate to reasoning-and-proving, but we excluded this material from analysis because it would be unwise to attempt to capture it all and difficult to know where to draw the line within the supplementary materials. Thus, this study does not characterize the entirety of each textbook series' geometry content but rather its canonical student edition lessons, described next. We believe this scope is meaningful because authors and publishers made decisions about what reasoning-and-proving opportunities to include in canonical lessons and which opportunities to place elsewhere.

All six textbooks contained numbered sections within each chapter and these sections contained expository text as well as student exercises. We refer to these textbook sections as lessons and they constituted the primary data of this study. Stratified random sampling was used to select the lessons for analysis, with the textbook chapters serving as strata. The random samples included a minimum of $30 \%$ of the lessons from each chapter. For example, we randomly selected 3 lessons when a chapter contained 10 total lessons (30\%) and 4 lessons when a chapter contained 11 total lessons (36\%). This resulted in actual samples of $32 \%-39 \%$ of lessons in each textbook and an overall sample of $212(37 \%)$ of the 580 total lessons. Our sampling procedure treated all chapters and lessons equally, even though they may not all have the same likelihood of being enacted (Tarr et al., 2006). As stated previously, this choice is based on our goal of characterizing opportunities to reason-and-prove in the textbooks themselves, not in classroom enactment. 
Table 2. Number of Lessons and Exercises Analyzed in Each Textbook

\begin{tabular}{lrrr} 
Textbook & Expository Lessons & Chapter Reviews & Exercises \\
\hline CME & 38 & 8 & 1058 \\
Glencoe & 33 & 13 & 2730 \\
Holt & 31 & 12 & 2531 \\
Key & 38 & 14 & 1489 \\
Prentice & 31 & 12 & 2479 \\
UCSMP & 41 & 14 & 2181 \\
Total & 212 & 73 & 12,468 \\
\hline
\end{tabular}

In addition to the expository lessons, we also included in our analysis one chapter review from each chapter of each textbook. We viewed chapter reviews as the textbook authors' sample of important concepts and procedures from the chapter, thus forming a complement to our own random sample of lessons. Several textbooks included more than one chapter review for each chapter, in which case we selected the one that appeared to be the most comprehensive of the chapter's expository content. Table 2 shows the number of sections analyzed for this study.

\section{Analytic Framework}

Following the recommendations of other textbook analysts (Li, 2000; Senk, Thompson, \& Johnson, 2008), our study included attention to both textbook exposition and student exercises because both contribute to the potential opportunities students have to engage with reasoning-and-proving. By textbook exposition, we mean the paragraphs of narrative text in the body of a lesson as well as the text-boxes that contain definitions, formulas, theorems, or key ideas. In essence, textbook exposition refers to the portions of a lesson in which the textbook authors are presenting information or ideas for consumption by a reader. Thus, worked examples (i.e., problems presented along with an explained solution) were considered to be part of the textbook exposition. By student exercise, we mean an item for which students are expected to take an active role by answering a question, solving a problem, or completing a particular task. The majority of student exercises were located in a separate section of a lesson (i.e., an exercise set) following the textbook exposition, but textbooks did have instances of student exercises interspersed with expository text. 
Thompson and colleagues (2012) developed an analytic framework based on NCTM's (2000) reasoning and proof process standard and the Third International Mathematics and Science Study (Valverde et al., 2002). This framework formed the basis of our own framework because it contained dimensions for both textbook exposition (which they referred to as "narrative") as well as student exercises, and because it distinguished meaningfully between various types of justifications and reasoning-and-proving activities. For the purposes of this study, however, it was necessary to make several modifications to their framework, described in detail next. The first of these modifications was based on the necessity principle (Harel \& Tall, 1991) and our desire to capture the nature of the mathematical statement around which the reasoning-and-proving opportunities were taking place. Another modification involved distinguishing between exercises that ask students to "explain" and those that ask students to "prove," which for Thompson and colleagues (2012) both fell under the develop an argument code. Other modifications involved only slight reinterpretations of existing categories and the inclusion of a few additional categories based on pilot analysis and the work of other researchers. We present our framework in its entirety (see Figure 1), prior to descriptions of the modifications, to orient the reader for the explication that follows.

\begin{tabular}{|c|c|c|c|}
\hline & \multirow{2}{*}{$\begin{array}{c}\text { Exposition } \\
\text { Properties, Theorems, } \\
\text { or Claims }\end{array}$} & \multicolumn{2}{|c|}{ Student Exercises } \\
\hline & & $\begin{array}{l}\text { Related to Mathematical } \\
\text { Claims }\end{array}$ & $\begin{array}{c}\text { Related to Mathematical } \\
\text { Arguments }\end{array}$ \\
\hline $\begin{array}{l}\text { Mathematical } \\
\text { Statement or } \\
\text { Situation }\end{array}$ & $\begin{array}{l}\text { - General } \\
\text { - Particular }\end{array}$ & $\begin{array}{l}\text { - General } \\
\text { - Particular } \\
\text { - General with particular } \\
\text { instantiation provided }\end{array}$ & $\begin{array}{l}\text { - General } \\
\text { - Particular } \\
\text { - General with particular } \\
\text { instantiation provided }\end{array}$ \\
\hline $\begin{array}{l}\text { Expected Student } \\
\text { Activity }\end{array}$ & & $\begin{array}{l}\text { - Make a conjecture, } \\
\text { refine a statement, or } \\
\text { draw a conclusion } \\
\text { - Fill in the blanks of a } \\
\text { conjecture } \\
\text { - Investigate a conjecture } \\
\text { or statement }\end{array}$ & $\begin{array}{l}\text { - Construct a proof } \\
\text { - Develop a rationale or other } \\
\text { non-proof argument } \\
\text { - Outline a proof or construct a } \\
\text { proof given an outline } \\
\text { - Fill in the blanks of an } \\
\text { argument or proof } \\
\text { - Evaluate or correct an } \\
\text { argument or proof } \\
\text { - Find a counterexample }\end{array}$ \\
\hline \multirow[t]{2}{*}{$\begin{array}{l}\text { Justification (or } \\
\text { environment for } \\
\text { exploration) }\end{array}$} & $\begin{array}{l}\text { - Deductive } \\
\text { - Empirical } \\
\text { - Outline } \\
\text { - Past or future } \\
\text { - Left to student } \\
\text { - None } \\
\end{array}$ & $\begin{array}{l}\text { - Deductive (explicit) } \\
\text { - Empirical (explicit) } \\
\text { - Implicit }\end{array}$ & $\begin{array}{l}\text { - Deductive (explicit) } \\
\text { - Empirical (explicit) } \\
\text { - Implicit }\end{array}$ \\
\hline & $\begin{array}{l}\text { - Statements about } \\
\text { reasoning-and-proving }\end{array}$ & \multicolumn{2}{|c|}{ - Exercises about reasoning-and-proving } \\
\hline
\end{tabular}

Figure 1. An analytic framework for reasoning-and-proving in geometry textbooks. 


\section{Characterizing Mathematical Statements}

The necessity principle (Harel \& Tall, 1991) highlights the importance of not only having students engage in deductive reasoning but also allowing students to experience the intellectual need for deduction. In mathematics, claims made about infinite classes of objects call for a shift away from inductive forms of reasoning that are prevalent outside mathematics. Two clarifications are in order for this interpretation of the necessity principle related to deductive reasoning. First, a focus on the need for deductive reasoning does not imply that inductive reasoning has no place in mathematical reasoning, but rather that deductive reasoning also has a place, especially with regard to the justification of claims about infinite classes as opposed to single or finite classes (Stylianides \& Ball, 2008). Second, the fact that claims involving infinite classes of mathematical objects have the potential to intellectually motivate deductive reasoning does not imply that deduction has no place with regard to finite claims. Indeed, deduction has value and is often used in reasoning about finite situations. Nonetheless, we are positing an intellectual link, broadly speaking, between claims involving infinite classes and deductive reasoning.

To capture in our analytic framework the issue of the motivation for deduction, we developed a category of codes relating to the mathematical statement or situation of reasoning-and-proving opportunities. This consideration of mathematical statements is complementary to past textbook analyses that focused solely on the activities expected of students. The codes for mathematical statements are general, particular, and general with particular instantiation provided (see Figure 2). Note that the inclusion of the words "general" and "particular" in the latter code is purposeful as this code reflects aspects of both general and particular situations.

In addition to the necessity principle, the field of logic also provides a rationale for distinguishing between these three types of mathematical statements in textbooks. In logic, if one selects an arbitrary element from a set, the notion of universal generalization allows for any conclusions drawn that do not appeal to specific characteristics of the selected element to be extended to the entire parent set (Hurley, 2006). Indeed, universal generalization is commonplace in mathematical proofs of general claims, as indicated by the typical format of first lines (e.g., "Let $n$ be a natural number," "Let $A B C$ be an arbitrary 


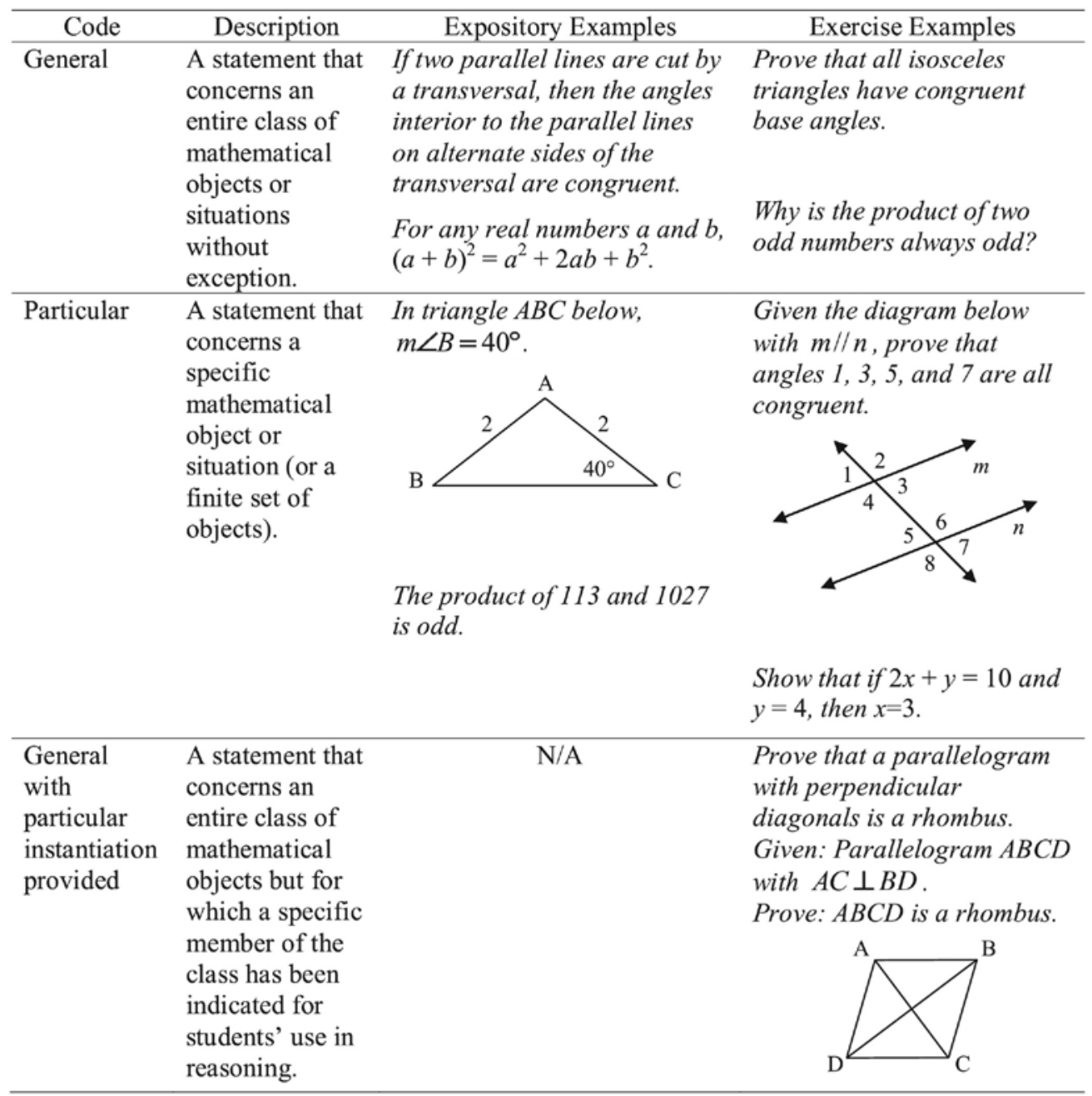

Figure 2. Types of mathematical statements for reasoning-and-proving opportunities.

right triangle"), but it is not required when justifying particular statements. The code of general with particular instantiation provided, then, captures the fact that general statements in textbooks may be accompanied by a preselected element from the set in question. In such cases, students do not necessarily have to take the step of universal generalization themselves but can use the specific element provided in the textbook. This feature of the written opportunity may be important if students do not realize that universal generalization is possible as they reason with the specific element. As a final point of clarification, it is important to realize that the instantiation referred to in this code is not a confirming example or diagram being produced as 
an initialization of a justification of a general claim, but rather a particular instance that satisfies the hypothesis stated in the statement (in geometry, this often does take the form of a diagram), which can subsequently be used by students in the justification process.

\section{Separating Mathematical Statements from Justifications}

The addition of statement-types to our framework allows us to make a clean separation between statement-type and justification-type. Because general statements and particular statements can both be justified deductively or empirically (although the justifications are not necessarily valid proofs), we view statement-type and justificationtype as independent dimensions (see Figure 3). To highlight this independence, we use the terms "general" and "particular" to refer exclusively to statements and the terms "deductive" and "empirical" to refer exclusively to justifications.

To solidify the separation of these dimensions, we depart from past textbook analyses (e.g., Thompson et al., 2012) by not inferring the nature of a students' justification from the nature of the statement they are justifying. In other words, we did not assume that general

\begin{tabular}{|c|c|c|}
\hline & Deductive Justification & Empirical Justification \\
\hline $\begin{array}{l}\text { General Statement } \\
\text { All isosceles triangles have } \\
\text { congruent base angles. }\end{array}$ & $\begin{array}{l}\text { Let } A B C \text { be an arbitrary } \\
\text { isosceles triangle with } A B \\
\text { and } A C \text { the congruent sides. } \\
\text { Since } \angle A \cong \angle A \text { reflexively, } \\
\text { triangle } A B C \text { is congruent to } \\
\text { triangle } A C B \text { by Side-Angle- } \\
\text { Side. Therefore, } \angle B \cong \angle C \\
\text { because these are } \\
\text { corresponding angles of the } \\
\text { congruent triangles. }\end{array}$ & $\begin{array}{l}\text { Measuring the base angles of } \\
\text { all of these isosceles triangles } \\
\text { confirms that the base angles of } \\
\text { isosceles triangles are } \\
\text { congruent. }\end{array}$ \\
\hline $\begin{array}{l}\text { Particular Statement } \\
\text { In the diagram below } \\
\text { where } m / / n \text {, the angles } 1 \text {, } \\
3,5 \text {, and } 7 \text { are congruent. }\end{array}$ & $\begin{array}{l}\text { By the Vertical Angle } \\
\text { theorem, } \angle 1 \cong \angle 3 \text { and } \\
\angle 5 \cong \angle 7 . \text { Furthermore, since } \\
\angle 1 \text { and } \angle 5 \text { are in } \\
\text { corresponding positions with } \\
\text { respect to the parallel lines } m \\
\text { and } n \text {, we know } \angle 1 \cong \angle 5 \text {. } \\
\text { Therefore, by the transitive } \\
\text { property of congruence, } \\
\angle 1 \cong \angle 3 \cong \angle 5 \cong \angle 7 \text {. }\end{array}$ & $\begin{array}{l}\text { I folded } \angle 1 \text { onto } \angle 3 \text { and they } \\
\text { corresponded exactly. Also, } \\
\angle 5 \text { and } \angle 7 \text { fold onto one } \\
\text { another perfectly. Then I } \\
\text { measured } \angle 1 \text { and } \angle 5 \text { with a } \\
\text { protractor to see that they have } \\
\text { the same measure. So then all } \\
\text { four of the angles are } \\
\text { congruent. }\end{array}$ \\
\hline
\end{tabular}

Figure 3. Statement-types and justification-types are independent categories of analysis. 
statements would be justified in general ways or particular statements in nongeneral ways, which means that findings related to the statement-type dimension of this analytic framework should not be construed as claims about resultant students' reasoning. Instead, we used the following codes to capture the type of justification that a student exercise called for, if such a call was made explicitly in the text:

- Deductive - the item explicitly calls for a "deductive argument" or a "logical chain" of justifications;

- Empirical - the item explicitly calls for measurements or confirming examples;

- Implicit - the item asks students to engage in reasoning-andproving (e.g., "Prove ..." or "Explain why ...") but does not explicitly specify the nature of the argument to be produced.

We acknowledge that, with these definitions, the majority of student exercises will fall in the implicit category with regard to justification type. Nevertheless, we feel that it is important to capture the reasoning-and-proving opportunities as explicitly represented in textbooks, especially because it is not clear that students interpret directions to "prove" or "show" in the same way that mathematicians or mathematics educators do. By using the implicit code rather than making assumptions about what students might produce, we are attempting to reduce inference in our analysis and to demarcate our study as one of textbook opportunities rather than student reasoning.

\section{Separating Opportunities to Prove from Opportunities to Explain}

Drawing on Stylianides' framework (2009) as well as others who have philosophically distinguished between proof and explanation (Dreyfus, 1999; Sierpinska, 1994), we divided Thompson and colleagues' (2012) category of develop an argument into two separate categories: construct a proof and develop a rationale or other non-proof argument. Within student exercises, we followed Hanna and de Bruyn (1999) and Bieda (2010) in using keywords as the primary means of distinguishing between these two categories. We associated terms such as "explain," "justify," "show," or "why" with develop a rationale or other non-proof argument and terms such as "prove" or "deduce" with construct a proof. Although we admit that it is possible for students to 
respond to an "explain" or "justify" prompt by providing a full mathematical proof-especially for those who recognize that proofs explain mathematical ideas (Hanna, 1990) - we maintain that the reasoningand-proving opportunities differ and thus reserved the category of construct a proof for those items in which the textbooks authors chose to explicitly invoke the notion of proof. For "explain," we coded only those items asking students to explain why something was true or false and not the items asking students to explain without a rationale the steps they carried out.

\section{Codes Inherited from Thompson, Senk, and Johnson}

The following codes from Thompson and colleagues (2012) for expected activity within student exercises were used with only slight modifications:

- Make a conjecture, refine a mathematical statement, or draw a conclusion-students are asked to formulate a mathematical claim or modify a false conjecture into one that the student believes is true. If students are also asked to support the resulting claim, an additional code or codes captures this supporting activity.

- Investigate a conjecture or statement-students are asked to determine the truth-value of a given conjecture or to determine the truth-value of something they just conjectured themselves.

- Evaluate or correct an argument or proof-an argument or proof is presented and students are asked to determine whether it is valid or to find the error(s) and correct them.

- Find a counterexample to a mathematical claim-students are asked to supply a counterexample that disproves a given mathematical claim.

With respect to exposition, there were also several codes from Thompson and colleagues (2012) that we included in our framework with minimal modification (e.g., renaming):

- Deductive justification - the textbook provides a logical argument building on definitions, postulates, or previously established results to support or prove a mathematical claim. 
- Empirical justification - the textbook provides a confirming example to a mathematical claim or infers the truth of the claim from a subset of the relevant cases.

- Justification left to student-rather than providing a justification in the textbook exposition, it is explicitly stated that students will be providing the justification (e.g., later in the exercise set).

- No justification-there is no justification for a given mathematical claim in the textbook exposition, and it is not explicitly stated that students will later produce a justification.

\section{Codes Added Based on Pilot Analysis of Geometry Textbooks}

Because reasoning-and-proving was expected to be more prevalent in geometry textbooks than other areas, we conducted pilot analysis and added the following categories of justification for textbook exposition:

- Outline - the textbook exposition contains an outline of a proof or the key step of a proof that would establish the truth of a mathematical claim.

- Past or future - rather than providing a justification in the textbook exposition, it is explicitly stated that a proof or other form of justification can be found in a past lesson or course, a future lesson or course, or somewhere external to the textbook (e.g., the Internet).

Within student exercises, we added the following categories of expected reasoning-and-proving activity:

- Fill in the blanks of a conjecture-students are asked to complete a mathematical conjecture for which a portion is already provided.

- Outline-students are asked to provide an outline of a proof or to write a full proof from a given outline.

- Fill in the blanks of an argument or proof - students are provided with a partial argument or proof and are asked to fill in the missing components, thus forming a complete argument or proof. 
Statements or Exercises About Reasoning-and-Proving

The final component of our analytic framework involved capturing the opportunities embedded in the geometry textbooks to reflect on or think about reasoning-and-proving as a mathematical practice. Following Hanna and de Bruyn (1999), who identified discussions about proof as separate from the act of proving, we coded statements about reasoning-and-proving and exercises about reasoning-and-proving as elements of textbook exposition and student exercises, respectively. These statements are pertinent to code because (a) geometry textbooks are perhaps the most likely place in school mathematics for reasoning-and-proving to become an explicit object of reflection, (b) many student difficulties around reasoning-and-proving involve the conception of the process itself, and (c) helping students become aware of the intellectual need for mathematical proof and deductive forms of reasoning, an aim suggested by the necessity principle, may involve giving students opportunities to reflect on the process rather than only engaging in it. Examples of this code involve the form of mathematical proofs (e.g., two-column proofs, flow proofs), the methods of proof (e.g., proof by contradiction) or forms of reasoning (e.g., inductive versus deductive), and explanations of strategies for constructing a proof (e.g., work backward). We recognize that many opportunities to reflect on reasoning-and-proving may be embedded in the teacher's guides rather than the student editions, but that is beyond the scope of the present study.

Having described the various components of the framework, we refer the reader back to Figure 1 for a visual depiction.

\section{Analytic Procedures}

Within each of the 212 lessons in our sample, we identified any expository mathematical statements such as theorems, postulates, properties, formulas, identities, or other claims of a mathematical truth (e.g., that a given diagram has a certain property). Mathematical definitions were not coded, but worked examples that included a prompt for reasoning-and-proving were coded as exposition. The statements included in analysis were then coded for their statementtype and their justification-type, with multiple codes being assigned 
if a single statement was justified multiple times. To check reliability, we performed double coding on a $20 \%$ subsample of lessons that yielded $95 \%$ agreement on statement-type and $91 \%$ agreement on justification-type within textbook exposition. It should be noted that, although postulates cannot be proven deductively, we included them in our analysis because they are mathematical claims and have interesting implications when considering the role of deductive arguments in establishing claims as true-postulates are accepted as true without deductive justification. This choice to include postulates means our analysis included more instances of no justification or empirical justification in textbook exposition than if we had excluded postulates, so we report postulates separately in the results.

For student exercises in the sampled lessons and chapter reviews, the reasoning-and-proving framework was taken to be exhaustive of the types of reasoning-and-proving items. In other words, if an item did not fall into one of the categories of reasoning-and-proving activity in Figure 1, we did not include it in our analysis. ${ }^{3}$ Examples of excluded items were those asking students to determine unknown measures in a given diagram, solve length or area problems, or identify geometric entities such as medians or orthocenters. Exercises that did involve at least one of the reasoning-and-proving activities, then, were subsequently coded for that activity as well as the type of mathematical statement involved and the type of justification expected. The unit of analysis was items as partitioned by numbers or letters in the textbook. So, for example, an exercise with parts a-d was considered as four separate items. A single item, however, could receive multiple codes if it involved multiple reasoning-and-proving activities (e.g., investigate a conjecture and provide a rationale). The reliability check in the case of student exercises yielded $92 \%$ agreement on statement-type and $93 \%$ agreement on activity-type. Because implicit codes were so prevalent for justification-type (as expected), results along this dimension are not reported in the results.

3. It is important to note that our analytic framework excludes patterning exercises (e.g., determine the hundredth entry in a given pattern) from reasoning-andproving, although Stylianides (2009) and Davis (2010) included such exercises in their studies of reform-oriented curricula. If, however, a geometry textbook asked students to conjecture or prove a statement based on a pattern, we included the item as reasoning-and-proving. 
With respect to items about reasoning and proving, exercises of this sort were coded but did not receive any other codes. Within textbook exposition, based on pilot analysis and issues of reliability, the unit of analysis for these codes was not the sentence level or the paragraph level but the theme level. For example, if multiple sentences were dealing with the same theme with respect to reasoning-and-proving, we assigned a single code, but if a paragraph contained two separable points relating to the practice of reasoning-and-proving, we coded two instances.

\section{Results}

In presenting the results, we first describe the reasoning-and-proving opportunities embedded in the geometry textbooks with respect to textbook exposition and then with respect to student exercises (RQ1). Generally speaking, opportunities to reason-and-prove were found to be more numerous than in textbooks for other levels of areas of mathematics but not as numerous as one might expect given the traditional link between reasoning-and-proving and geometry. The frequencies of opportunities to construct a proof and to think about reasoning-and-proving were especially low.

Next, we present an analysis of similarities and differences across the exposition and exercises with regard to the nature of reasoningand-proving opportunities in these two contexts (RQ2). The most striking result in this case was that general mathematical statements constitute the majority of reasoning-and-proving items in exposition, but particular statements were more common in student exercises. Moreover, when general statements did appear in exercises, a substantial portion of them came with a particular instantiation provided, which has implications for the intellectual necessity of proof and the steps of deductive reasoning.

For the results overall, reasoning-and-proving opportunities are treated in aggregate for entire textbooks, but this is not to say that the opportunities were distributed evenly over the chapters of the textbooks. Elsewhere (Otten, Males, \& Gilbertson, in press) we take up this specific issue through an analysis of the opportunities in certain chapters in contrast to others. 


\section{Reasoning-and-Proving in Textbook Exposition}

Table 3 reports for each textbook the frequency of reasoning-andproving items appearing in the expository sections, such as theorems, postulates, certain worked examples, or statements about reasoningand-proving. However, direct comparison of frequencies between the textbooks are problematic for a variety of reasons, and we therefore turn to more detailed results of reasoning-and-proving in textbook exposition.

\section{Types of Statements in Textbook Exposition}

Table 4 shows the types of mathematical statements that appeared related to reasoning-and-proving in textbook exposition. General statements were prevalent in the exposition sections of all six textbooks.

Table 3. Frequency of Reasoning-and-Proving Items in Textbook Exposition

\begin{tabular}{lccc} 
Textbook & $\begin{array}{c}\text { No. of Expository } \\
\text { Lessons Analyzed }\end{array}$ & $\begin{array}{c}\text { No. of Reasoning-and- } \\
\text { Proving Items }\end{array}$ & $\begin{array}{c}\text { Reasoning-and-Proving } \\
\text { Items per Lesson }\end{array}$ \\
\hline CME & 38 & 95 & 2.5 \\
Glencoe & 33 & 172 & 5.2 \\
Holt & 31 & 154 & 5.0 \\
Key & 38 & 130 & 3.4 \\
Prentice & 31 & 138 & 4.5 \\
UCSMP & 41 & 218 & 5.3 \\
\hline
\end{tabular}

Note: Chapter reviews are not included as expository lessons.

Table 4. Types of Statements in Textbook Exposition

\begin{tabular}{lcccc} 
Textbook & $\begin{array}{c}\text { No. of General Statements }(\%) \\
\text { Non-Postulate }\end{array}$ & $\begin{array}{c}\text { No. of Particular } \\
\text { Ptatements (\%) }\end{array}$ & $\begin{array}{c}\text { No. of Statements About } \\
\text { Reasoning-and-Proving (\%) }\end{array}$ \\
\hline CME & $69(64)$ & $8(8)$ & $13(14)$ & $13(14)$ \\
Glencoe & $109(63)$ & $10(6)$ & $45(26)$ & $8(5)$ \\
Holt & $94(61)$ & $8(5)$ & $37(24)$ & $15(10)$ \\
Key & $73(56)$ & $35^{*}(27)$ & $8(6)$ & $14(11)$ \\
Prentice & $87(63)$ & $16(12)$ & $28(20)$ & $7(5)$ \\
UCSMP & $146(67)$ & $11(5)$ & $20(9)$ & $41(19)$ \\
\hline
\end{tabular}

* Approximately half of Key's postulates came from a single lesson that listed postulates from algebra and related postulates in geometry. 
In Key, $83 \%$ of statements were general in nature while only $6 \%$ were about particular objects or situations. Even in Glencoe and Holt, where the percentage of general statements was the lowest, there were still more than two general statements for every one particular statement. Key (6\%), UCSMP (9\%), and CME (14\%) had relatively few statements of a particular nature in their expository sections.

In all books, particular statements related to reasoning-and-proving were predominantly worked examples. For example, Prentice contained a worked example of a proof about a particular quadrilateral (see Figure 4) that used the Hypotenuse-leg theorem, introduced earlier in the same expository section.

There was variability between textbooks in the frequency of statements about the practice of reasoning-and-proving. UCSMP had the highest percentage of such statements (19\%), with an average of 1 statement about reasoning-and-proving every lesson. An example of such a statement from UCSMP is when the textbook authors pointed out "the difference between proof and disproof" (p. 96, emphasis in original) in that the latter only requires one counterexample, whereas the former requires more than confirming examples. In a later chapter, following a worked example that contained a proof, UCSMP also noted that "[ $\mathrm{t}$ ]he last statement of the proof in Example 2 is imperative. ... You must justify why your calculations prove the statement that is to be proved" (p. 671). Holt (10\%) had 1 statement about reasoning-and-proving every 2 lessons and both Key $(11 \%)$ and CME (14\%) had approximately 1 such statement every 3 lessons. For Glencoe (5\%) and Prentice (5\%), these averages were 1 for every 4-5 lessons.

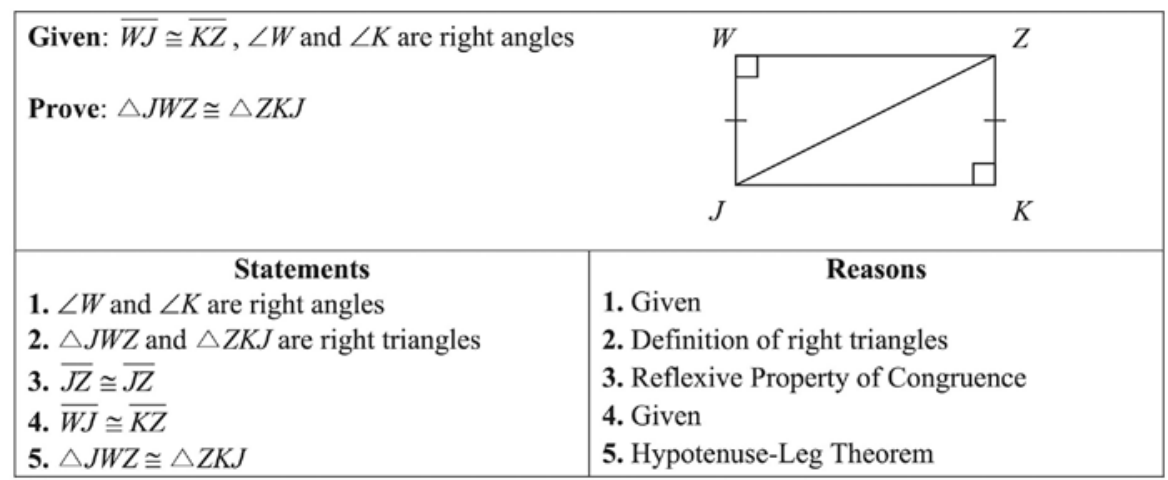

Figure 4. A worked example adapted from Prentice (p. 237) containing a particular statement being proved deductively. 


\section{Types of Justifications in Textbook Exposition}

With the exception of statements about the practice of reasoning-andproving, each reasoning-and-proving item in the textbook exposition was coded for the type of justification provided (see Table 5). Deductive arguments were used to justify $42 \%$ of the reasoning-and-proving items in UCSMP and 36\% of the items in both Holt and Prentice. Glencoe employed deductive justifications $30 \%$ of the time and CME did so $27 \%$ of the time. Key was the only textbook to use empirical arguments (55\%) more frequently than deductive arguments (19\%), although CME had a nearly even split with $24 \%$ empirical to $27 \%$ deductive. Holt and Glencoe were the least likely to give empirical arguments at $9 \%$ and $16 \%$, respectively, but they were also the most likely to leave the justification to the student ( $26 \%$ and $34 \%$, respectively).

In addition to deductive and empirical arguments, the other primary justification codes were no justification or explicitly stating that the students would be expected to supply an argument. Glencoe left the justification to students most often (34\%), whereas Key (5\%) and UCSMP (4\%) did so least often. Key was the least likely textbook to omit a justification, doing so for only $9 \%$ of the reasoning-and-proving statements. The other five textbooks omitted justifications approximately $20 \%-30 \%$ of the time. When interpreting the omission of justifications, one should refer to Table 4 to the number of postulates coded in each textbook because these were usually and understandably presented without justification. In some instances (particularly in Key), however, empirical support for a postulate was given or a reference was made to the students having learned the postulate in a past course.

Table 5. Percentages of Justification-Types in Textbook Exposition

\begin{tabular}{lcccccc} 
Textbook & $\begin{array}{c}\text { Deductive } \\
\text { Argument }\end{array}$ & $\begin{array}{c}\text { Empirical } \\
\text { Argument }\end{array}$ & Outline & $\begin{array}{c}\text { Left to } \\
\text { Student }\end{array}$ & $\begin{array}{c}\text { Past or } \\
\text { Future }\end{array}$ & $\begin{array}{c}\text { Not } \\
\text { Justified }\end{array}$ \\
\hline CME & 27 & 24 & 5 & 17 & 12 & 28 \\
Glencoe & 30 & 16 & 0 & 34 & 8 & 17 \\
Holt & 36 & 9 & 0 & 26 & 7 & 25 \\
Key & 19 & 55 & 3 & 5 & 15 & 9 \\
Prentice & 36 & 26 & 2 & 14 & 8 & 24 \\
UCSMP & 42 & 24 & 1 & 4 & 13 & 27 \\
\hline
\end{tabular}

Note: Rows sum to more than 100 because a statement may be justified in multiple ways. 


\section{Summary}

The six geometry textbooks contain approximately 2.5 to 5 reasoning-and-proving statements per expository lesson. Of these reasoning-and-proving statements, roughly three-quarters involved a general class of mathematical objects (e.g., theorems or formulas), that is, the types of statements that arguably lay the foundation for pedagogy that necessitates deductive forms of reasoning. There were relatively few statements of a particular nature in the textbook exposition, and when such statements did occur they were usually in the form of worked examples. Justifications in the textbook exposition were divided fairly evenly between deductive arguments, empirical arguments, left-to-student, and no justification. Exceptions to this relatively even distribution of justifications were the following: Holt, which tended not to employ empirical arguments; Key, which employed many empirical arguments; and UCSMP, which provided more deductive arguments and left less to the students than the other textbooks.

\section{Reasoning-and-Proving in Student Exercises}

Our analysis validated the assumption that reasoning-and-proving is most prevalent in secondary-level geometry as reasoning-and-proving exercises constituted one-fifth to two-fifths of the total student exercises, which is a substantially higher portion than found in other areas (Davis, 2010; Thompson et al., 2012; Stylianides, 2009). Table 6 contains frequencies of reasoning-and-proving exercises in each of the textbooks.

Table 6. Frequency of Reasoning-and-Proving Exercises

\begin{tabular}{lcccc} 
Textbook & $\begin{array}{c}\text { No. of } \\
\text { Lessons } \\
\text { Analyzed }\end{array}$ & $\begin{array}{c}\text { No. of } \\
\text { Exercises } \\
\text { Analyzed }\end{array}$ & $\begin{array}{c}\text { No. of Reasoning- } \\
\text { and-Proving } \\
\text { Exercises (\%) }\end{array}$ & $\begin{array}{c}\text { Reasoning-and- } \\
\text { Proving Exercises } \\
\text { per Lesson }\end{array}$ \\
\hline CME & 46 & 1058 & $400(38)$ & 8.7 \\
Glencoe & 46 & 2730 & $663(24)$ & 14.4 \\
Holt & 43 & 2531 & $597(24)$ & 13.9 \\
Key & 52 & 1489 & $397(27)$ & 7.6 \\
Prentice & 43 & 2479 & $484(20)$ & 11.3 \\
UCSMP & 55 & 2181 & $601(28)$ & 10.9 \\
\hline
\end{tabular}

Note. Lessons in this table include chapter reviews. 
CME, which had the lowest frequency of reasoning-and-proving statements in exposition, had the highest percentage of reasoning-andproving exercises (38\%), whereas Prentice had the lowest percentage (20\%). Glencoe and Holt, the textbooks with the most total exercises (see Table 2), had the highest frequencies of reasoning-and-proving exercises per lesson at 14.4 and 13.9, respectively. Key and CME, the textbooks with the least exercises analyzed, had the lowest frequencies per lesson (7.6 and 8.7, resp.). Note throughout this section that, as noted previously, these exercises only represent potential opportunities to engage in reasoning-and-proving as there can be great variability between and within textbooks with respect to the exercises actually assigned by teachers and actually completed by students.

\section{Types of Statements in Student Exercises}

As Table 7 shows, particular statements were prevalent in the exercises of all six textbooks. In Holt, $72 \%$ of reasoning-and-proving exercises involved a particular mathematical statement. For example, in Holt (p. 324), students were asked to show that, within the triangle with vertices of $(-6,11),(6,-3)$, and $(-2,-5)$, the segment connecting the midpoints of two sides of the triangle is parallel to and half the length of the third side; this exercise involves reasoning only around that specific triangle. Similarly, Prentice, Glencoe, and UCSMP included particular statements in approximately $60 \%-65 \%$ of reasoning-and-proving exercises. Figure 5 depicts an example of a particular statement in a proof exercise from Glencoe. Key and CME, on the other hand, approximated a balanced split between general statements and particular statements.

Table 7. Types of Statements in Reasoning-and-Proving Exercises

\begin{tabular}{lcccc} 
Textbook & $\begin{array}{c}\text { No. of } \\
\text { General } \\
\text { Statements (\%) }\end{array}$ & $\begin{array}{c}\text { No. of } \\
\text { Particular } \\
\text { Statements (\%) }\end{array}$ & $\begin{array}{c}\text { No. of General } \\
\text { Statements with } \\
\text { Instantiation (\%) }\end{array}$ & $\begin{array}{c}\text { No. of Exercises } \\
\text { about Reasoning- } \\
\text { and-Proving (\%) }\end{array}$ \\
\hline CME & $181(45)$ & $206(52)$ & $9(2)$ & $4(1)$ \\
Glencoe & $180(27)$ & $398(60)$ & $68(10)$ & $17(3)$ \\
Holt & $117(20)$ & $430(72)$ & $33(5)$ & $17(3)$ \\
Key & $174(44)$ & $190(48)$ & $20(5)$ & $13(3)$ \\
Prentice & $130(27)$ & $315(65)$ & $37(8)$ & $14(2)$ \\
UCSMP & $214(36)$ & $351(58)$ & $22(4)$ & \\
\hline
\end{tabular}




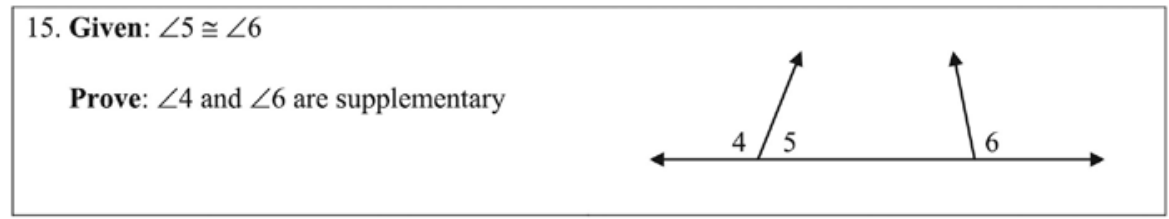

Figure 5. An adapted example of a particular statement in a reasoning-and-proving exercise from Glencoe (p. 155).

A modest number of exercises involved reasoning-and-proving around a general statement with a particular instantiation provided by the textbook. For instance, Holt asked students to prove the Exterior Angle theorem, which is stated generally, but then provided a particular labeled diagram for students to work with (see Figure 6). The category of general statements with particular instantiation becomes more noteworthy when one compares it with the number of general statements rather than the total number of reasoning-andproving exercises. Specifically, of the reasoning-and-proving exercises in Glencoe, Prentice, and Holt that involved some form of general mathematical statement, $27 \%, 22 \%$, and $22 \%$ provided a particular instantiation for the students to reason with, respectively. As for exercises about the practice of reasoning-and-proving, none of the textbooks exceeded $3 \%$ of reasoning-and-proving exercises being of this variety. In terms of total exercises analyzed, the portion is less than 1 in 180 exercises.

\section{Types of Reasoning-and-Proving Activities in Student Exercises}

Past studies of reasoning-and-proving in textbooks focused on the types of activities expected of students. Table 8 follows this convention by depicting the percentages of various reasoning-and- proving
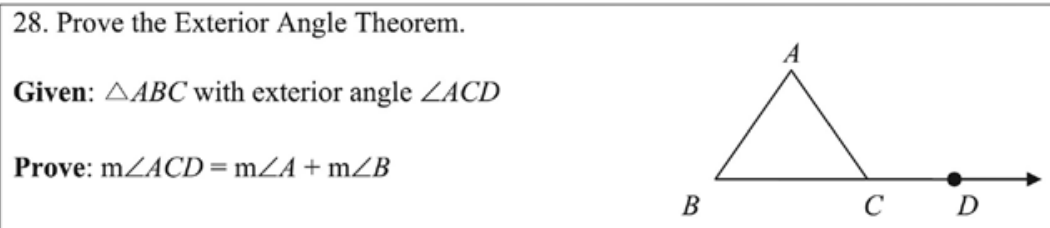

Figure 6. An adapted example of a general exercise with a particular instantiation provided in the Holt textbook (p. 229). 
Table 8. Percentages of Activity-Types in Reasoning-and-Proving Exercises

\begin{tabular}{lcccccc} 
Textbook & $\begin{array}{c}\text { Construct } \\
\text { a Proof }\end{array}$ & $\begin{array}{c}\text { Develop a } \\
\text { Rationale }\end{array}$ & $\begin{array}{c}\text { Find a } \\
\text { Counterexample }\end{array}$ & $\begin{array}{c}\text { Investigate a } \\
\text { Statement }\end{array}$ & $\begin{array}{c}\text { Make a } \\
\text { Conjecture }\end{array}$ & Other \\
\hline CME & 25 & 36 & 7 & 44 & 16 & 3 \\
Glencoe & 28 & 48 & 4 & 30 & 17 & 5 \\
Holt & 13 & 42 & 4 & 39 & 8 & 16 \\
Key & 13 & 52 & 26 & 42 & 20 & 6 \\
Prentice & 15 & 54 & 1 & 46 & 19 & 11 \\
UCSMP & 14 & 44 & 3 & 36 & 14 & 5 \\
\hline
\end{tabular}

Note: Rows sum to more than 100 because an exercise may involve multiple activities.

activities found in the six geometry textbooks we examined. Note that Table 8 should be interpreted with regard to Table 6 because the latter indicates how many reasoning-and-proving items were identified overall, which form the basis of the percentages in Table 8 .

In four of the textbooks, $13 \%-15 \%$ of their reasoning-and-proving exercises (or 3\%-4\% of their total exercises) involved students constructing a proof. In CME and Glencoe, proof comprised 25\% and 28\% of their reasoning-and-proving exercises, respectively (or 9\% and 7\% of their total exercises). The most common reasoning-and-proving activities were to investigate a statement (i.e., determine the truth-value of a mathematical claim) and to develop a rationale (i.e., to explain or justify an answer or result in a manner that is not necessarily a proof). With the exception of Holt (8\%), approximately $15 \%-20 \%$ of reasoning-and-proving exercises involved students making a conjecture.

\section{Statement-Types of Proof-Focused Exercises}

It is worthwhile to consider the interaction between activity-type and statement-type in student exercises, particularly with regard to exercises that deal explicitly with proof, captured by the following codes: construct a proof, outline a proof or construct a proof given an outline, fillin-the-blanks of an argument or proof, and evaluate or correct an argument or proof. Of these explicitly proof-focused exercises, Figure 7 depicts the breakdown of general statements, particular statements, and general statements with particular instantiations provided.

Prentice, Holt, and UCSMP had approximately two-thirds of proof-focused exercises take place around particular statements. 


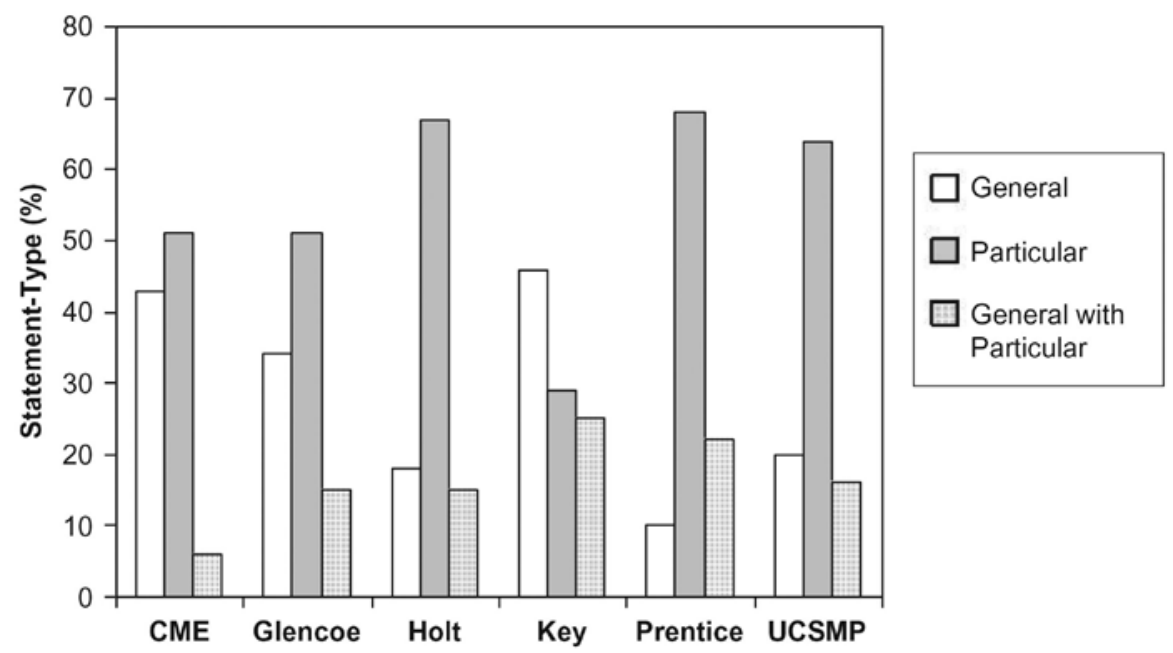

Figure 7. Percentages of statements-types of those reasoning-and-proving exercises explicitly focusing on proof.

Furthermore, within these three textbooks, a sizeable portion of the nonparticular statements were presented with a particular instantiation for the student to reason with, removing the need for students to engage in the step of universal generalization. In CME and Glencoe, approximately one-half of proof-focused exercises took place around particular statements, although Glencoe provided more particular instantiations for general statements than did CME. Key stood out as having the lowest percentage of particular proof-focused exercises $(29 \%)$, but it also had the highest percentage of proof-focused exercises in which a particular instantiation was provided for a general statement $(25 \%)$.

\section{Summary}

Most reasoning-and-proving exercises took place around particular mathematical statements rather than general statements, and of the general statements a sizeable portion had particular instantiations provided for students. In both the particular and general-with-particular-instantiation-provided situations, reasoning can occur around a single or finite number of cases and so deductive reasoning is not necessitated to the same degree as with general statements. It should be noted, however, that Key and CME approached a balanced split between general and particular statements. The most common reasoning-and-proving activities asked of students were determining 
the truth-value of a mathematical claim and providing explanations or other nonproof justifications of mathematical statements. In two books (CME and Glencoe) at least one-quarter of the reasoning-andproving exercises asked students to construct a proof; in the other books, such items comprised only $13 \%-15 \%$ of the reasoning-andproving items. Of the exercises explicitly dealing with proof, all textbooks except Key were more likely to have such exercises involve a particular mathematical statement than a general one.

\section{Comparing Textbook Exposition to Student Exercises}

Although it is possible for textbook exposition to be enacted in such a way that students actively participate in developing the expository material-indeed, this seems to be the intention behind the design of CME (Cuoco, 2007) and Key (Key Curriculum Press, 2008)it remains reasonable to assume that students will, to some extent, be readers or recipients of the expository content. By the same token, one might expect students to take a more active part in the written exercises than in the textbook exposition. Because of this distinction, we turn our attention in this section to a comparison between the results of the textbook exposition and the student exercises.

Figure 8 compares textbook exposition and student exercises with respect to the percentage of reasoning-and-proving items that were general in nature for each portion of the textbook. For example, in

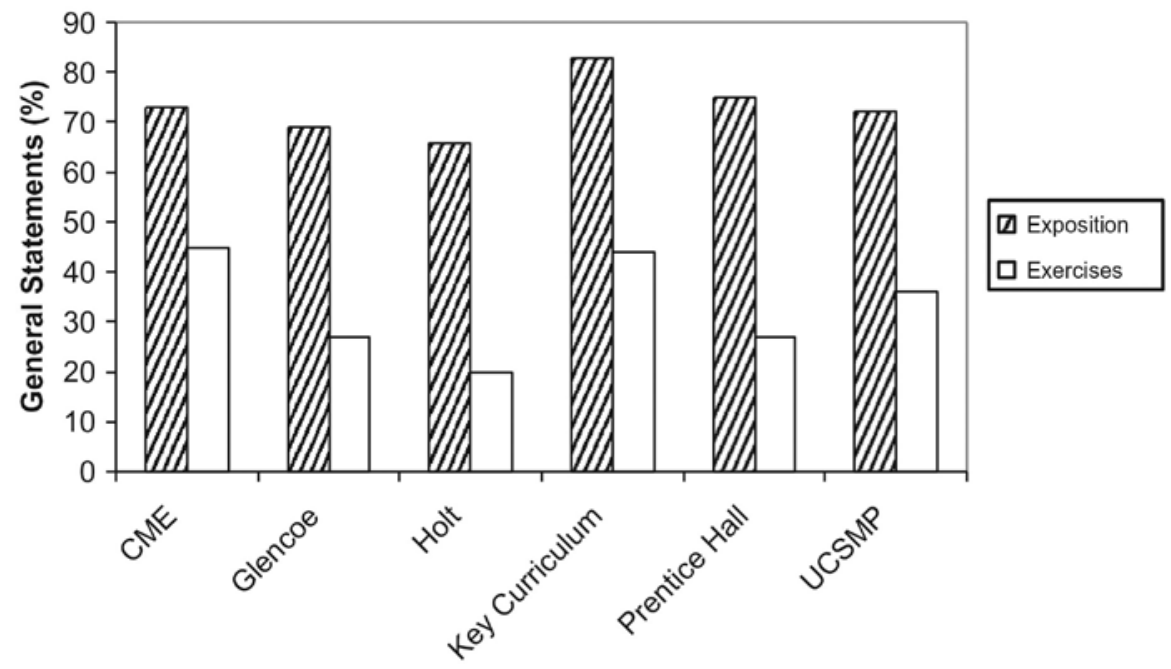

Figure 8. The nature of mathematical statements in textbook exposition versus student exercises. 
$\mathrm{CME}, 73 \%$ of reasoning-and-proving items in the exposition involved general statements, whereas $45 \%$ of reasoning-and-proving exercises involved such statements. Figure 8 reveals a stark contrast between the types of mathematical statements represented in the textbook exposition and those in the student exercises: at least two-thirds of the reasoning-and-proving items in the exposition, and as many as fourfifths were general in nature. In contrast, less than half and even as little as one-fifth of the statements within the reasoning-and-proving exercises were general. Furthermore, when particular statements did appear in expository sections they were usually in the form of worked examples (see Figure 6, for example), which may be interpreted as the textbook authors presenting what would otherwise be considered a student exercise. Conversely, when general statements appeared in student exercises, they were often accompanied by a particular instantiation of the general claim, which does not lay the same foundation for adherence to the necessity principle. In other words, the gap between statement-types in exposition versus exercises grows rather than shrinks when we consider nuanced factors such as worked examples and particular instantiations.

Of the mathematical claims presented in textbook expositions, many were justified deductively but many were also justified empirically. Within the exercises, the type of justification to be provided by the student was most often left implicit. If we assume that students interpret "prove" to be calling for a deductive argument, then there were a fair number of opportunities for students to develop deductive arguments. "Explain" exercises, however, were much more common than "prove" exercises and it is unclear whether students interpret prompts to explain as opportunities to employ a deductive line of reasoning. Also with regard to justification, five textbooks' exposition included no justification for approximately one-quarter of their mathematical statements, although some of these were likely postulates. (In Key, this was true for only 9\% of such statements.) Similarly, there were many exercises that asked students to make a conjecture or determine the truth-value of a mathematical claim without also asking the students to explain, justify, or prove that claim. For example, in Key, students were asked to complete the following statement, which Key referred to as a conjecture: "If two angles are both congruent and supplementary, then ?" (p. 125). They were not asked to justify this conjecture. Many textbooks gave sets of claims and asked students 
to decide if they were always true, sometimes true, or never true, but did not require a justification for these decisions (although at other times, they may have been accompanied by requests for justification).

Finally, concerning statements or exercises about the practice of reasoning-and-proving, there was strong similarity between the expository sections and the student exercises in that such opportunities were rare in both places. Less than one-quarter of the analyzed expository lessons contained even a single comment about reasoning-and-proving as a mathematical practice. Only UCSMP had a sizeable number of such statements, with at least one appearing in $40 \%$ of their sampled lessons. Likewise, less than $0.6 \%$ of the analyzed exercises asked students to reflect on or write about the reasoning-andproving process. These frequencies may be viewed as low for secondary-level geometry texts because this is typically the setting in school mathematics where students learn about the reasoning process and mathematical proof most explicitly.

\section{Discussion}

In this article, we have shared results of an investigation of the reasoning-and-proving opportunities embedded in six different U.S. geometry textbooks. Overall, approximately one-quarter of the textbook exercises analyzed asked students to engage in reasoning-andproving activities, and the construction of a proof was entailed in less than $5 \%$. These percentages are higher than have been found in even the most proof-focused sections of U.S. algebra and pre-calculus textbooks (Thompson et al., 2012), a middle school textbook series (Stylianides, 2009), and an integrated high school textbook series (Davis, 2010). For geometry, however, which typically represents the high point of reasoning-and-proving opportunities in the school curriculum (Hanna \& de Bruyn, 1999; Herbst, 2002), these quantities of reasoning-and-proving opportunities may be viewed as limited in light of the calls for reasoning-and-proving to be integral to the school mathematics curriculum (NCTM, 2000, 2009; NGA \& CCSSO, 2010) and the fact that proof specifically is present in $24 \%$ of the Common Core State Standards geometry standards (Kosko \& Herbst, 2011). Moreover, deductive arguments were provided for less than half the claims coded in textbook exposition, which extends a finding 
of Thompson and colleagues (2012) in nongeometry textbooks, where approximately $30 \%$ of expository properties were justified deductively. The scope of our study, however, does not allow for inferences to be made with regard to ideal proportions of certain kinds of reasoning-and-proving opportunities, and as the design of our analytic framework has emphasized, it is important to consider not only the quantity of the reasoning-and-proving opportunities but their quality in terms of helping students see the intellectual need for this important mathematical practice.

With the exception of UCSMP, statements or questions about reasoning-and-proving as a mathematical practice were rare. Such opportunities have the potential to not only allow students to reflect on the nature of their mathematical activity but also to develop metacognitive skills that have been shown to be important in the reasoning-and-proving process (Schoenfeld, 1992; Weber, 2001). This scarcity suggests students' opportunities, as reflected in curriculum materials, to actively engage in reasoning-and-proving outweigh their opportunities to reflect on reasoning-and-proving. Hence it becomes even more important to examine the nature of the opportunities to actively reason-and-prove. Are such experiences representative of the disciplinary practice of reasoning-and-proving? Do they lay a foundation for pedagogy that adheres to the necessity principle with respect to deductive reasoning? These questions stretch beyond the specific U.S. context of the present study.

The most common reasoning-and-proving activities were providing a rationale (not necessarily a proof) and determining the truthvalue of a mathematical claim. ${ }^{4}$ That is, students had many more opportunities to make judgments about the truth of a claim than they did to provide deductive arguments - the disciplinary process by which truth is established. From the perspective of the necessity principle (Harel \& Tall, 1991), it may be insufficient to ask students

4 With respect to the prominence of rationale exercises, one might contend that an "explain" prompt provides students with an opportunity to construct a proof because a key function of mathematical proofs is explanation (de Villiers, 1995; Hanna, 1995). This leads to the question, however, of whether students realize that a proof would be an effective response to a rationale exercise. Answering this question would take us beyond the realm of textbook analysis, although we can note that Herbst and Brach (2006) found that geometry students viewed proof tasks to be distinct from explanation tasks. 
to frequently indicate the truth or falsity of mathematical statements, and presumably come to conviction about that truth or falsity, without also providing a justification or with only a prompt for a nonrigorous explanation.

This is not to say that there was a complete absence of opportunities to engage in the development of deductive justifications. These opportunities, however, were most commonly around a particular mathematical statement or, at other times, around a general statement with a particular instantiation provided. Such exercises, we contend, do not necessitate deductive forms of reasoning to the same extent as exercises around general statements. ${ }^{5}$ When a student is faced with a particular diagram of parallel lines cut by a transversal, for example, and is asked to show that a specific angle in the given diagram measures $40^{\circ}$, it is not unreasonable to approach this situation by using a protractor to measure the angle in question. Indeed, this approach makes a great deal of sense if the context were the practical world. Mathematics, however, is unique in its concern for general claims - in this case, assertions about any pair of parallel lines cut by an arbitrary transversal - where inductive reasoning falters and deductive reasoning is needed.

Much of the existing literature on students' abilities and conceptions with respect to reasoning-and-proving is consonant with our finding that particular statements are prevalent in student exercises. For example, although there are exercises that ask students to prove or justify mathematical claims, the paucity of exercises that necessitate deductive forms of reasoning suggests that students, even after their secondary-level geometry course, may have difficulty producing proofs and may continue to rely on empirical forms of reasoning (e.g., Chazan, 1993; Harel \& Sowder, 2007; Herbst \& Brach, 2006; Selden \& Selden, 2003). Moreover, this may partially explain why Senk (1985) found in her large-scale study of proof performance among U.S. geometry students that students were more successful in proving particular statements than general statements.

5 These proof opportunities around particular statements, although they may achieve many of the state standards for proof in geometry, do not seem to align with the new proof standards as outline in the Common Core State Standards (NGA \& CCSSO, 2010). As Kosko and Herbst (2011) noted, the Common Core proof standards often relate to important pieces of content in such a way that these standards are not likely to be met with "token proof exercises whose conclusions are not memorable" (p. 7). 
Herbst and Brach (2006), in a study of geometry students, found that students were more confident that they would be accountable for proving a statement presented in Given-Prove format than for proving a general statement such as "a line through the midpoints of two sides of a triangle is parallel to the third side and half its length" (p. 84). Furthermore, the students in their study tended not to accept responsibility for proving propositions that contained key mathematical ideas, such as those that we found predominantly in textbook exposition. Moreover, Soucy McCrone and Martin (2009) interviewed geometry students who reported that the purpose of proof is merely to apply recently learned theorems. If these students had been using a textbook from this study, their perception is justifiable-we found it to be uncommon for students to have opportunities to prove important mathematical results but typical for them to have opportunities to use established theorems to prove something about particular situations.

One might argue that it is necessary for key mathematical results (i.e., general statements) to be explicated in expository sections so that they may be officially recognized in the classroom canon and, moreover, that it is necessary to provide students with numerous particular statements to prove because practice is essential and there are not enough relevant general statements to allow for an adequate amount of reasoning-and-proving practice. In response to these points, we would draw attention to the fact that this is essentially an argument in favor of the status quo with respect to reasoning-and-proving instruction, and the research as well as the policy documents we have cited in this article indicate that the current state of reasoning-andproving in geometry is not producing the student outcomes that the international mathematics education community hopes to see. In the end, our collective goal is not only for students to have success with reasoning-and-proving but also to see its intellectual necessity and its value in mathematics.

We wish to explicitly state that none of the textbook trends identified in this study are inherently good, bad, beneficial, or problematic. With respect to statement types, although reasoning-and-proving around particular statements may not necessitate deduction to the same degree as general statements, they may provide rich opportunities for teachers to help students see the general in the particular 
(Mason \& Pimm, 1984) and "think big" even as they are "talking small” (Cuoco, Goldenberg, \& Mark, 1996, p. 384). Particular statements can form a basis for enacting meaningful shifts to more general types of reasoning. As Reid and Knipping (2010) pointed out, proofs in geometry often fall between generic arguments, wherein an example represents a larger class, and symbolic arguments, wherein words and abstract symbols represent the class, because in geometry there is often a reliance on a specific diagram. This intersection of argument-types relates to the statement-type that we coded as general statements accompanied by particular instantiations. Although such opportunities to reason-and-prove open up the possibility of students omitting the logical step of universal generalization, they can be enacted in productive ways to draw attention to precisely that issue of selecting an arbitrary element with which to reason about an entire set. This process may help students develop the habit of "thinking small" as they "talk big" (Cuoco et al., 1996). Moreover, this study examined only proportions of various types of opportunities and did not attend to the sequencing of activities, which may be important with regard to students' learning of reasoning-and-proving. Nonetheless, rather than ascribing value to the written opportunities, we are claiming in this article that an awareness of the nature of such reasoning-and-proving opportunities is important both for teachers, researchers, and curriculum developers. Moreover, students may benefit from having explicit discussions about these issues.

In conclusion, this study makes two primary contributions to the research on reasoning-and-proving in school mathematics textbooks. First, by characterizing the nature and extent of reasoning-and-proving opportunities in U.S. geometry textbooks, this study complements the work that has already been done outside of geometry (Davis, 2010; Stylianides, 2009; Thompson et al., 2012). Second, we have used the necessity principle to guide the development of a refined framework for textbook analysis that takes into account the types of mathematical statements within reasoning-and-proving opportunities. Future research may use this refined framework to investigate the reasoning-and-proving opportunities in content areas other than geometry or in contexts other than the United States. We have also identified apparent consonances between our findings and existing research on students' performance and conceptions with respect to 
reasoning-and-proving, but research focused on the links between reasoning-and-proving opportunities in curriculum materials and the reasoning-and-proving activities of the enacted and attained curriculum is required to empirically confirm these connections.

Acknowledgments - A portion of the results contained herein were presented at the 33rd annual meeting of the North American Chapter of the International Group for the Psychology of Mathematics Education. The authors would like to thank Kris-

ten Bieda and Sharon Senk for their helpful comments and conversations during the course of this study.

Funding - This work was supported with funding from the College of Natural Science, Michigan State University.

\section{References}

Bass, L. E., Charles, R. I., Hall, B., Johnson, A., \& Kennedy, D. (2009). Prentice Hall mathematics: Geometry. Boston, MA: Pearson Prentice Hall.

Bell, A.W. (1976). A study of pupils' proof-explanations in mathematical situations. Educational Studies in Mathematics, 7, 23-40.

Benson, J., Klein, R., Miller, M. J., Capuzzi-Feuerstein, C., Fletcher, M., Marino, G., et al. (2009). Geometry. Chicago, IL: Wright Group McGraw Hill.

Bieda, K. N. (2010). Enacting proof-related tasks in middle school mathematics: Challenges and opportunities. Journal for Research in Mathematics Education, 41, 351-382.

Bieda, K. N., Drwencke, J., \& Picard, A. (in press). Reasoning-and-proving opportunities in elementary mathematics textbooks. International Journal of Educational Research.

Bieda, K., Holden, C., \& Knuth, E. (2006). Does proof prove?: Students' emerging beliefs about generality and proof in middle school. In Proceedings of the 28th annual meeting of the North American Chapter of the International Group for the Psychology of Mathematics Education. Merida, Mexico, 395-402.

Buchbinder, O., \& Zaslavsky, O. (2011). Is this a coincidence? The role of examples in fostering a need for proof. ZDM, 43, 269-281.

Burger, E. B., Chard, D. J., Kennedy, P. A., Leinwand, S. J., Renfro, F. L., Roby, T. W., et al. (2011). Geometry. Orlando, FL: Holt McDougal.

Carter, J. A., Cuevas, G. J., Day, R., Malloy, C., \&Cummins, J. (2010). Geometry. Columbus, OH: Glencoe/McGraw-Hill.

Chazan, D. (1993). High school geometry students' justification for their views of empirical evidence and mathematical proof. Educational Studies in Mathematics, 24, 359-387.

CME Project. (2009). Geometry. Upper Saddle River, NJ: Pearson Education.

Cohen, D. K., Raudenbush, S. W., \& Ball, D. L. (2003). Resources, instruction, and research. Educational Evaluation and Policy Analysis, 25, 119-142. 
Cuoco, A. (2007). The case of the CME Project. In C.R. Hirsch (Ed.), Perspectives on the design and development of school mathematics curricula (pp. 119-127). Reston, VA: National Council of Teachers of Mathematics.

Cuoco, A., Goldenberg, E. P., \& Mark, J. (1996). Habits of mind: An organizing principle for mathematics curricula. Journal of Mathematical Behavior, 15, 375-402.

Davis, J. D. (2010). A textual analysis of reasoning and proof in one reformoriented high school mathematics textbook. In P. Brosnan, D. B. Erchick, \& L. Flevares (Eds.), Proceedings of the 32nd annual meeting of the North American Chapter of the International Group for the Psychology of Mathematics Education (pp. 844-851). Columbus, OH: Ohio State University.

de Villiers, M. D. (1995). An alternative introduction to proof in dynamic geometry. MicroMath, 11(12), 14-19.

Dossey, J., Halvorsen, K., \& Soucy McCrone, S. (2008). Mathematics education in the United States 2008: A capsule summary fact book. Reston, VA: National Council of Teachers of Mathematics.

Dreyfus, T. (1999). Why Johnny can't prove. Educational Studies in Mathematics, 38(1/3), 85-109.

Fischbein, E. (1982). Intuition and proof. For the Learning of Mathematics, 3(2), 9-24.

Floden, R. E. (2002). The measurement of opportunity to learn. In A. C. Porter \& A. Gamoran (Eds.), Methodological advances in cross-national surveys of educational achievement (pp. 231-266). Washington, DC: National Academy Press.

Fujita, T., Jones, K., \& Kunimune, S. (2009). The design of textbooks and their influence on students' understanding of "proof" in lower secondary school. In F.-L. Lin, F.-J. Hsieh, G. Hanna, \& M. de Villiers (Eds.), Proceedings of the ICMI Study 19 Conference: Proof and proving in mathematics education (Vol. 1, pp. 172177). Taipei, Taiwan: National Taiwan Normal University.

Grouws, D. A., Smith, M. S., \& Sztajn, P. (2004). The preparation and teaching practices of United States mathematics teachers: Grade 4 and 8. In P. Kloosterman \& F. K. Lester, Jr. (Eds.), Results and interpretations of the 19902000 mathematics assessments of the National Assessment of Educational Progress (pp. 221-267). Reston, VA: National Council of Teachers of Mathematics.

Hanna, G. (1990). Some pedagogical aspects of proof. Interchange, 21(1), 6-13.

Hanna, G. (1995). Challenges to the importance of proof. For the Learning of Mathematics, 15(3), 42-49.

Hanna, G. (2000). Proof, explanation and exploration: An overview. Educational Studies in Mathematics, 44, 5-23.

Hanna, G., \& de Bruyn, Y. (1999). Opportunity to learn proof in Ontario grade twelve mathematics texts. Ontario Mathematics Gazette, 38, 180-187.

Hanna, G., \& de Villiers, M. (2008). ICMI Study 19: Proof and proving in mathematics education. ZDM, 40, 329-336.

Harel, G., \& Sowder, L. (2007). Toward comprehensive perspectives on the learning and teaching of proof. In F. K. Lester, Jr. (Ed.), Second handbook of research on mathematics teaching and learning (pp. 805-842). Charlotte, NC: Information Age Publishing. 
Harel, G., \& Tall, D. (1991). The general, the abstract, and the generic in advanced mathematics. For the Learning of Mathematics, 11(1), 38-42.

Healy, L., \& Hoyles, C. (2000). A study of proof conceptions in algebra. Journal for Research in Mathematics Education, 31, 396-428.

Heinze, A., Cheng, Y.-H., Ufer, S., Lin, F.-L., \& Reiss, K. (2008). Strategies to foster students' competencies in constructing multi-steps geometric proofs: Teaching experiments in Taiwan and Germany. ZDM, 40, 443-453.

Herbel-Eisenmann, B. A. (2007). From intended curriculum to written curriculum: Examining the "voice" of a mathematics textbook. Journal for Research in Mathematics Education, 38, 344-369.

Herbst, P. G. (2002). Establishing a custom of proving in American school geometry: Evolution of the two-column proof in the early twentieth century. Educational Studies in Mathematics, 49, 283-312.

Herbst, P., \& Brach, C. (2006). Proving and doing proofs in high school geometry classes: What is it that is going on for students? Cognition and Instruction, 24, 73-122.

Hersh, R. (2009). What I would like my students to already know about proof. In D. A. Stylianou, M. L. Blanton, \& E. J. Knuth (Eds.), Teaching and learning proof across the grades: A K-16 perspective (pp. 17-20). New York, NY: Routledge.

Hirsch, C. (Ed.) (2007). Perspectives on the design and development of school mathematics curricula. Reston, VA: National Council of Teachers of Mathematics.

Hurley, P. J. (2006). A concise introduction to logic (9th ed.). Belmont, CA: Thomson Learning.

Husen, T. (1967). International Study of Achievement in Mathematics: A comparison of twelve countries (Vol. 1). New York, NY: John Wiley \& Sons.

Key Curriculum Press. (2008). Tracing proof in Discovering Geometry. Retrieved June 1, 2011, from http://keypress.com/x5233.xml

Kosko, K. W., \& Herbst, P. (2011). Where's the proof? Proof in U.S. high school geometry content standards. In T. Lamberg \& L. Wiest (Eds.), Proceedings of the 33rd annual meeting of the North American Chapter of the International Group for the Psychology of Mathematics Education (pp. 329-337). Reno, NV: University of Nevada at Reno.

Lakatos, I. (1976). Proofs and refutations: The logic of mathematical discovery. Cambridge, UK: Cambridge University Press.

Lampert, M. (1990).When the problem is not the question and the solution is not the answer: Mathematical knowing and teaching. American Educational Research Journal, 27, 29-63.

Li, Y. (2000). A comparison of problems that follow selected content presentations in American and Chinese mathematics textbooks. Journal for Research in Mathematics Education, 31, 234-241.

Martin, M. O., \& Kelly, D. L. (Eds.). (1998). TIMSS technical report: Implementation and analysis: Final year of secondary school (Vol. 3). Chestnut Hill, MA: Boston College.

Martin, W. G., \& Harel, G. (1989). Proof frames of preservice elementary teachers. Journal for Research in Mathematics Education, 20, 41-51. 
Mason, J., \& Pimm, D. (1984). Generic examples: Seeing the general in the particular. Educational Studies in Mathematics, 15, 277-289.

McCrory, R., Francis, A., \& Young, S. (2008, July). Resource use by instructors of mathematics classes for future elementary teachers. Paper presented at the 11th meeting of the International Committee on Mathematics Instruction, Monterrey, Mexico.

Ministry of Education, Science and Technology. (2011). The 2011 revised (Korean) national curriculum of mathematics. Official notification number 2011-351.

Muis, K. R. (2004). Personal epistemology and mathematics: A critical review and synthesis of research. Review of Educational Research, 74, 317-377.

National Council of Teachers of Mathematics. (2000). Principles and standards for school mathematics. Reston, VA: Author.

National Council of Teachers of Mathematics. (2009). Focus in high school mathematics: Reasoning and sense making. Reston, VA: Author.

National Governors Association Center for Best Practices, \& Council of Chief State School Officers. (2010). Common Core State Standards for Mathematics. Washington, DC: Author.

Ni, Y., \& Cai, J. (2011). Searching for evidence of curricular effect on the teaching and learning of mathematics: Lessons learned from the two projects. International Journal of Educational Research, 50, 137-143.

Öner, D. (2008). A comparative analysis of high school geometry curricula: What do technology-intensive, Standards-based, and traditional curricula have to offer in terms of mathematical proof and reasoning? Journal of Computers in Mathematics and Science Teaching, 2008, 467-497.

Öner, D. (2009). The role of dynamic geometry software in high school geometry curricula: An analysis of proof tasks. International Journal for Technology in Mathematics Education, 16, 109-121.

Otten, S., Males, L. M., \& Gilbertson, N. G. (in press). The introduction of proof in secondary geometry textbooks. International Journal of Educational Research.

Polya, G. (1959). Mathematics as a subject for learning plausible reasoning. Mathematics Teacher, 52, 7-9.

Polya, G. (1981). Mathematical discovery. New York, NY: John Wiley \& Sons.

Porteous, K. (1990). What do children really believe? Educational Studies in Mathematics, 21, 589-598.

Recio, A. M., \& Godino, J. D. (2001). Institutional and personal meanings of mathematical proof. Educational Studies in Mathematics, 48, 83-99.

Reid, D. A., \& Knipping, C. (2010). Proof in mathematics education: Research, learning and teaching. Boston, MA: Sense Publishers.

Schoenfeld, A. H. (1988). When good teaching leads to bad results: The disasters of "well-taught" mathematics courses. Educational Psychologist, 23, 145-166.

Schoenfeld, A. H. (1992). Learning to think mathematically: Problem solving, metacognition, and sense making in mathematics. In D. A. Grouws (Ed.), Handbook of research on mathematics reaching and learning (pp. 334-370). New York, NY: Macmillan.

Selden, A., \& Selden, J. (2003). Validations of proofs considered as texts: Can undergraduates tell whether an argument proves a theorem? Journal for Research in Mathematics Education, 34, 4-36. 
Senk, S. L. (1985). How well do students write geometry proofs? Mathematics Teacher, 78, 448-456.

Senk, S. L., Thompson, D. R., \& Johnson, G. J. (2008, July). Reasoning and proof in high school textbooks from the USA. Paper presented at the Meeting of the International Congress on Mathematics Education, Monterey, Mexico.

Serra, M. (2008). Discovering geometry: An investigative approach (4th ed.). Emeryville, CA: Key Curriculum Press.

Shield, M., \& Dole, S. (2013). Assessing the potential of mathematics textbooks to promote deep learning. Educational Studies in Mathematics, 82, 183-199.

Sierpinska, A. (1994). Understanding in mathematics. London, UK: Falmer Press.

Soucy McCrone, S. M., \& Martin, T. S. (2009). Formal proof in high school geometry: Student perceptions of structure, validity, and purpose. In D. A. Stylianou, M. L. Blanton, \& E. J. Knuth (Eds.), Teaching and learning proof across the grades: A K-16 perspective (pp. 204-221). New York, NY: Routledge.

Sowder, L., \& Harel, G. (1998). Types of students' justifications. Mathematics Teacher, 91, 670-675.

Stein, M. K., Remillard, J., \& Smith, M. S. (2007). How curriculum influences student learning. In F. K. Lester, Jr. (Ed.), Second handbook of research on mathematics teaching and learning (pp. 319-369). Charlotte, NC: Information Age Publishing.

Stylianides, A. J., \& Ball, D. L. (2008). Understanding and describing mathematical knowledge for teaching: Knowledge about proof for engaging students in the activity of proving. Journal of Mathematics Teacher Education, 11, 307-332.

Stylianides, G. J., \& Stylianides, A. J. (2009). Facilitating the transition from empirical arguments to proof. Journal for Research in Mathematics Education, 40, 314-352.

Stylianides, G. J. (2009). Reasoning-and-proving in school mathematics textbooks. Mathematical Thinking and Learning, 11, 258-288.

Stylianou, D. A., Blanton, M. L., \& Knuth, E. J. (Eds.). (2009). Teaching and learning proof across the grades: A K-16 perspective. New York, NY: Routledge.

Tarr, J. E., Chavez, O., Reys, R. E., \& Reys, B. J. (2006). From the written to the enacted curricula: The intermediary role of middle school mathematics teachers in shaping students' opportunity to learn. School Science and Mathematics, 106, 191-201.

Thompson, D. R., Senk, S. L., \& Johnson, G. J. (2012). Opportunities to learn reasoning and proof in high school mathematics textbooks. Journal for Research in Mathematics Education, 43, 253-295.

Trends in International Mathematics and Science Study (TIMSS). (1998). Data almanacs for achievement items: Percent correct on the advanced mathematics items: Final year of secondary school. Retrieved from http://timss.bc.edu/timss1995i/ TIMSSPDF/pc alm95/m12alm95.pdf

Tinto, P. (1988, April). Students' views on learning proof in high school geometry. Paper presented at the Annual Meeting of the American Educational Research Association, New Orleans, LA. 
Valverde, G. A., Bianchi, L. J., Wolfe, R. G., Schmidt, W. H., \& Houang, R. T. (2002). According to the book: Using TIMSS to investigate the translation of policy into practice through the world of textbooks. Dordrecht, The Netherlands: Kluwer Academic Publishers.

Vincent, J., \& Stacey, K. (2008). Do mathematics textbooks cultivate shallow teaching? Applying the TIMSS video study criteria to Australian Eighth-grade mathematics textbooks. Mathematics Education Research Journal, 20(1), 82-107.

Weber, K. (2001). Student difficulty in constructing proofs: The need for strategic knowledge. Educational Studies in Mathematics, 48, 101-119.

Williams, E. (1980). An investigation of senior high school students' understanding of the nature of mathematical proof. Journal for Research in Mathematics Education, 11, 165-166. 